\title{
Derince Eğitim ve Araştırma Hastanesi Kadın Hastalıkları ve Doğum Kliniği'ne Başvuran Gebelerde Gestasyonel Diyabet Sıklığı ve Perinatal Sonuçları
}

\author{
The Prevalence and Perinatal Results of Gestational Diabetes Mellitus in Pregnant Women Who \\ were Admitted to Derince Teaching and Research Hospital Obstetric and \\ Gynecology Department \\ Arzu YAVUZ1', Ömer DEMIRTAŞ², Hasan TERZi' ${ }^{1}$ Nilüfer TUNCAY IŞIKKENT' ${ }^{1}$, Ahmet KALE ${ }^{1}$ \\ ${ }^{1}$ Kocaeli Derince Eğitim ve Araştırma Hastanesi, Kadın Hastalıkları ve Doğum Kliniği, Kocaeli \\ ${ }^{2}$ Pamukkale Üniversitesi Tıp Fakültesi Hastanesi, Kadın Hastalıkları ve Doğum Kliniği, Denizli
}

\begin{abstract}
öz
Amaç: Çalışmamızın amacı hastanemiz kadın hastalıkları ve doğum polikliniklerine rutin gebelik takibi için başvuran hastalarda gestasyonel diyabetes mellitus (GDM) sıklığını araştırmak ve bu olguların perinatal sonuçlarını analiz etmektir.

Gereç ve Yöntem: Bu çalışmada Kocaeli Derince Eğitim ve Araştırma Hastanesine, Temmuz 2012-Mart 2013 yılları arasında kadın hastalıkları ve doğum polikliniğine başvuran, rutin diyabet taraması uygulanmış 526 hastanın perinatal sonuçları retrospektif olarak incelenmiştir. Hastaların hepsine 50 gram glukoz tolerans testi (GTT) uygulanmış ve sonuçları anormal olanlarda 100 gram oral glukoz tolerans testi (100 gr OGTT) yapılmıştır. Hastalar ACOG kriterlerine göre GDM olmayan (Grup 1) ve GDM olan (Grup 2) iki gruba ayrılmış ve hastalar yaş, gravida, parite, abortus, doğum haftası, bebek kilosu, bebek boyu, 1. ve 5. dakika Apgar skorları açısından karşılaştırılmıştır.
\end{abstract}

Bulgular: Çalışmaya dahil edilen 526 hastanın 46 (\% 8,7) sında GDM saptanmıştır. 145 hastada (\%27.5) ise $50 \mathrm{gr}$ tarama testi yüksek bulunmuştur. İstatistiksel analizde yaş, abort sayısı ve bebek kiloları ve doğum şekillerinde farklılık saptanmıştır. Anne yaşı, abort sayıları, bebek kiloları ve sezaryen oranları grup 2 de daha yüksek bulunmuştur.

Sonuç: Kliniğimize başvuran gebelerin GDM prevalansı \%8,7 dir. Bizim çalışmamızda, anne yaşının GDM için önemli bir risk faktörü olduğunu, bebek doğum kilolarının ve sezaryen oranlarının diyabetik annelerde daha yüksek olduğunu tespit ettik.

Anahtar Kelimeler: Gestasyonel diyabet, prevalans, perinatal sonuçlar.
Objective: The aim of this study was to determine gestational diabetes mellitus (GDM) frequency and perinatal results of these patients whom referred to our hospital's antepartum clinic for routine follow-up.

Material and Methods: In this study perinatal results of 526 pregnant women who attended to our antepartum clinic for routine follow-up between July 2012 and March 2013 were analyzed retrospectively. A 50-g glucose challenge test (GCT) applied at 24-28 weeks' gestation. The patients who had a value of blood glucose $\geq 140 \mathrm{mg} /$ dl undergone 100-g oral glucose tolerance test (OGTT). Patients were divided in two groups according to ACOG GDM criteria. Group 1 was not GDM and group 2 was that diagnosed as GDM. These groups were compared according to maternal age, gravidity, parity, abortus, gestational weeks at birth, rates of cesarean section, cesarean indications, birth weight, birth height and 1. and 5. minute Apgar scores.

Results: Of the 526 pregnant women 46 patients di 7 agnosed as GDM (8,7\%). One hundred forty five patients had abnormal $50 \mathrm{gr}$ GTT results (27,5\%). Maternal age, abortus, birth weight and cesarean rates were found different in statistically analysis. These parameters were detected higher in group 2 patients.

Conclusion: The prevalence of GDM in pregnant women who were admitted to our clinic was $8,7 \%$. In our study we found that maternal age was an important risc factor for GDM and birth weight, cesarean rates were higher in diabetic patients.

Keywords: Gestational diabetes mellitus, prevalence, perinatal results. 


\section{GíRiş}

Gestasyonel diyabetes mellitus (GDM), ilk kez gebelikte tanısı konulan ya da gebelik sırasında ortaya çıkan karbonhidrat intoleransı olarak tanımlanmaktadır (1-3). Diyabet, gebelikte en sık görülen medikal komplikasyondur (4). Gebelikte görülen diyabetin \%90'ına yakın birkısmı GDM'dir. Türkiye'de değişik yörelerde yapılan çalışmalarda, GDM prevalansının \% 3-8 arasında değiştiği saptanmıştır (5). GDM sıklığı maternal yaş, etnik özellikler ve obeziteyle ilişkili olarak artabilmektedir (6). Böylesine sık görülmesi ve perinatal morbiditeyi ve mortaliteyi önemli derecede etkileyebilmesi nedeniyle GDM önemli bir sağlık sorunu olarak karşımıza çıkmaktadır.

GDM'ye bağlı olarak polihidramnios, preeklampsi, preterm eylem, pyelonefrit, makrozomik fetus ve bununla ilişkili doğum travması, sezaryen sıklığında artış meydana gelebilir (7). Uzun dönemde ise bu hastalarda Tip II diyabetes mellitus(DM) gelişme riski vardır (8). GDM'de kan şekeri düzeyleri regüle edildiğinde fetuste ortaya çıkabilecek fetal makrozomi, omuz distosisi, doğum travması, sezaryen sıklığındaki artış ve yenidoğan döneminde ortaya çıkan hipoglisemi, polisitemi, hipokalsemi ve hiperbilirubinemi gibi metabolik komplikasyonlar önlenebilir.

Bu çalışmadaki amacımız, kliniğimize başvuran hastalardaki GDM sıklığını araştırmak ve GDM saptanan olgular ile normal gebeler arasındaki demografik özelliklerin ve perinatal sonuçların karşılaştırılmasıdır.

\section{GEREÇ ve YÖNTEM}

Çalışmamıza, Temmuz 2012 ve Mart 2013 tarihleri arasında Kocaeli Derince Eğitim ve Araştırma Hastanesi kadın hastalıkları ve doğum polikliniğine gebelik takipleri için başvurup GDM taraması yapılan ve daha sonra hastanemizde doğumları gerçekleştirilen 526 hasta dahil edilmiştir. Hastaların verilerine retrospektif olarak bilgisayar kayıtları aracılığı ile ulaşılmıştır. Gebelik haftasını belirleme işlemi son adet tarihine ve ilk trimesterde yapılmış ultrasonografik ölçümlere göre yapıldı.
Günümüzde GDM ile ilgili tanı ve tarama konsensusu olmamakla beraber, kliniğimizde ACOG önerilerine uygun olarak tüm gebelere 24-28 hafta arasında 50 gram glukoz tarama testi uygulanmaktadır (9). 50 gram glukoz tarama testinde 1 . saat değeri $\geq 140 \mathrm{mg} / \mathrm{dl}$ olan olgulara, 100 gram OGTT yapılmıştır. GDM tanısı, 100 gram oral glukoz tolerans testi (OGTT) sonrası Carpenter ve Coustan (CC) kriterlerine göre 2 veya daha fazla anormal değer (0. Saat 95, 1. saat 180 , 2. saat $155,3$. saat $140 \mathrm{mg} / \mathrm{dl}$ ) saptanmasıyla konulmuştur. GDM tanısı, ayrıca 50 gram glukoz yükleme testinde 1 . saat sonrası glukoz değeri $\geq 200$ $\mathrm{mg} / \mathrm{dl}$ olan olgularda konulmuştur. GDM tanısı almayan olgular grup1, GDM tanısı alanlar ise grup 2 olarak sınıflandırılmıştır. GDM olgularına diyet uygulanmış ve kan şekeri değerleri ile kontrol yapılmıştır. İnsülin tedavisi açlık ve postprandiyal kan glukoz değerleri (açlık 95 $\mathrm{mg} / \mathrm{dl}$, postprandiyal 1 . saat $140 \mathrm{mg} / \mathrm{dl}$ ) rutin olarak aşıldığında başlanmıştır.

$\mathrm{Bu}$ çalışmada maternal yaş, gravida, parite, abortus gibi maternal demografik özellikler yanında doğum haftası, doğum şekli, sezaryen endikasyonları, bebek kilosu ve boyu, 1. ve 5. dakika Apgar skorları değerlendirilmiştir. Olgular tekil gebelik olup, çoğul gebelik, gebelik öncesi diyabeti veya başka sistemik hastalığı olan olgular ile bilgileri eksik olan olgular çalışma dışı bırakılmıştır. Ancak obezite, ileri anne yaşı, GDM öyküsü, makrozomik doğum öyküsü, diyabet aile öyküsü gibi risk faktörü olanlar ise dışlanmamıştır.

Sürekli veriler ortalama \pm standart sapma ve minimum-maksimum olarak ifade edilmiştir. Normal dağılım gösteren sürekli veriler bağımsız t-test kullanılarak analiz edildi. Non-parametrik veriler ise ki-kare yöntemi ile değerlendirildi. Tüm testlerde $p<0,05$ istatistiksel olarak anlamlı kabul edildi. Verilerin istatistiksel analizinde SPSS(Chicago, USA) paket 16.0 programı kullanıldı.

\section{BULGULAR}

Çalışmamızda, kadın doğum polikliniklerimize rutin kontrollerine gelen, 24-28. gebelik haftaları arasında GDM taraması yapılan ve hastanemizde doğumları gerçekleştirilen 526 
gebenin demografik özellikleri ve perinatal sonuçları incelenmiştir. Yüz kırk beş $(\% 27,5)$ hastanın $50 \mathrm{gr}$ GTT sonucunun anormal olduğu tespit edilmiş, 526 gebenin 46(\%8,7) 'sının 100 gr OGTT sonucu GDM olduğu bulunmuştur. $50 \mathrm{gr}$ GTT ve $100 \mathrm{gr}$ OGTT değerleri tablo 1 de sunulmuştur (Tablo 1). Hastalarımızın ortalama yaşları 28,02 $\pm 5,4$ yıl, gravida sayısı 2,2 $\pm 1,1$, parite sayısı $1,04 \pm 0,9$ ve abortus sayısı $0,2 \pm 0,5$ olarak tespit edilmiştir. GDM tanısı almış olan gebelerin \% 15.2'sinde (46 olgunun 7'si) insülin tedavisine gereksinim duyulurken, diğerlerine diyetle birlikte egzersiz tedavisi yeterli olmuştur.

\begin{tabular}{|c|c|c|c|}
\hline & Grup 1 & Grup 2 & p value \\
\hline $\begin{array}{l}50 \text { gr GTT } \\
\text { 0. saat şekeri }\end{array}$ & $84,2 \pm 7,8$ & $93,7 \pm 9,1$ & $n d$ \\
\hline $\begin{array}{l}50 \text { gr GTT } \\
\text { 1. saat şekeri }\end{array}$ & $119,2 \pm 26,5$ & $181,3 \pm 26,5$ & nd \\
\hline $\begin{array}{l}100 \text { gr GTT } \\
\text { 0. saat șekeri }\end{array}$ & $87,2 \pm 7,3$ & $92,3 \pm 10,3$ & nd \\
\hline $\begin{array}{l}100 \text { gr GTT } \\
\text { 1. saat şekeri }\end{array}$ & $157,1 \pm 22,9$ & $198,4 \pm 15,9$ & $n d$ \\
\hline $\begin{array}{l}100 \text { gr GTT } \\
\text { 2. saat şekeri }\end{array}$ & $131,1 \pm 18,4$ & $161,2 \pm 26,4$ & $n d$ \\
\hline $\begin{array}{l}100 \text { gr GTT } \\
\text { 3. saat şekeri }\end{array}$ & $96,4 \pm 23,5$ & $110,4 \pm 30,5$ & $n d$ \\
\hline
\end{tabular}

GRUP 1:ACOG kriterlerine göre normal olan grup. GRUP 2: ACOG kriterlerine göre GDM tanss alan grup

Perinatal sonuçlar ve yenidoğan açısından değerlendirildiğinde 526 hastanın ortalama doğum haftaları 39 $\pm 1,4$ hafta, doğum kiloları $3309,7 \pm 471,9$ gram, 1. dakika Apgar skorları

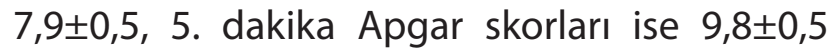
olarak bulunmuştur. Grup 1 ve grup 2 nin sırası ile yaş, gravida, parite, abortus, doğum haftası, bebek kilosu, bebek boyu, 1. ve 5 . dakika Apgar skorları hesaplanmış ve ki-kare testi ile karşılaştırmaları yapılmıştır (Tablo 2). İstatistiksel analizde anneyaşı, abort sayısı, bebek kiloları ve doğum şekilleri arasındafarklılık saptanmıştır. Grup 2 de anne yaşı daha ileri, abort sayıları ve bebek kiloları daha fazla idi. Grup 1 deki 480 hastanın $214(\% 44,6)^{\prime}$ ünde, Grup 2 deki 46 hastanın $34(\% 73,9)^{\prime}$ ünde doğum sezaryen ile gerçekleştirilmiştir. Normal doğum için, Grup 1 deki sayımız $266(\% 55,4)$ iken, grup 2 de bu sayı $12(\% 26,1)$ idi. GDM tanısı alan hastaların sezaryen ile doğum oranları fazla idi. Doğum şekli açısından da istatistiksel anlamlılık bulunmuştur $(p<0,001)$. Sezaryen ile doğum yapanların endikasyonlarına bakıldığında ise gruplar arasında bir fark bulunamadı (Tablo 3).

Tablo 2: Hastaların demografik verileri ve perinatal sonuçları

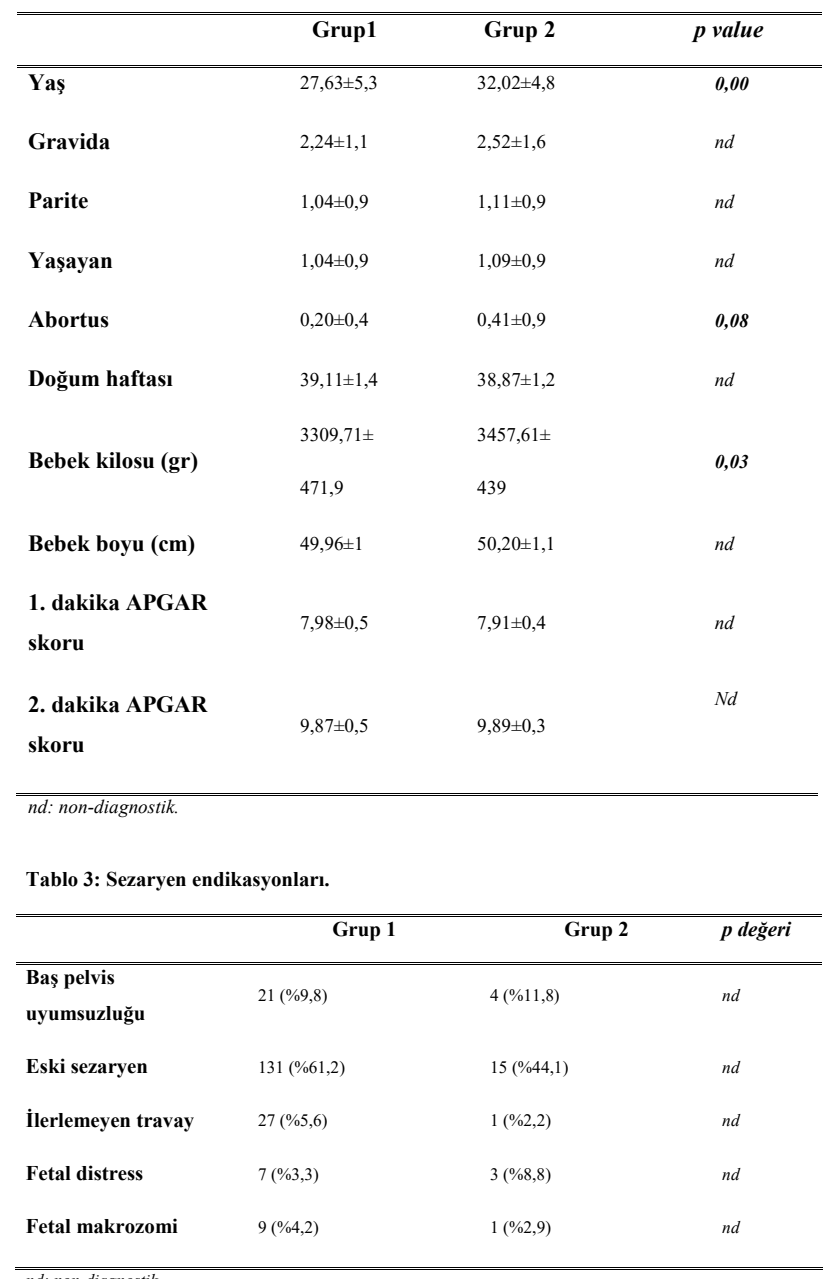

\section{TARTIŞMA}

Diyabet ile komplike olmuş gebelikler hem maternal hem fetal açıdan dikkatli takip gerektiren riskli gebeliklerdir. Elli gram GTT, tarama amacıyla kullanılan bir testtir. Eşik değer 140 mg/dl kabul edildiğinde gestasyonel diyabeti olanların \% 80'i, $130 \mathrm{mg} / \mathrm{dl}$ olarak alınırsa \% 90'ı tanınabilir. Eşik değerin 140 mg/ dl olduğu grupta yalancı pozitiflik oranı \% 1418 iken, eşiğin $130 \mathrm{mg} / \mathrm{dl}$ kabul edildiği grupta bu oran \% 20-25tir. GDM olan hastaların \% 10'unun tarama değerlerinin 130-139 mg/ dL arasında olduğu literatürde bildirilmiştir (10, 11). Biz çalışmamızda 140 mg/dl'yi sınır olarak aldık ve $50 \mathrm{gr}$ GTT pozitifliğini \% 27,5 olarak bulduk. Siribaddana ve arkadaşlarının yaptıkları çalışmada 50 gr GTT pozitifliği \% 18 olarak bildirilmiştir (12). Bizim çalışmamızda bu oranı daha yüksek bulmamızın sebebi risk 
faktörü olan hastaların dışlanmamış olması ile açıklanabilir.

Yaptığımız çalışmada GDM prevalansını \%8,7 olarak bulduk. Özyurt ve arkadaşları da yaptıkları çalışmada, benzer şekilde GDM sıklığını \% 9.2 bulmuşlardır. Türkiye'de daha önce değişik bölgelerde yapılmış olan ve OGTT sonuçlarının bizim çalışmamızda olduğu gibi CC kriterlerine göre değerlendirilmiş olduğu çalışmalarda, GDM prevalansının \% 3-8 arasında değiştiği saptanmıştır (5). Bu çalışmalardaki gebelerin, yaşları, pariteleri çalışmamızdaki olgularla benzer olmasına rağmen, GDM prevalansının daha düşük bulunmasının nedeni çalışmamızda risk faktörü olan olguların dışlanmaması ayrıca beslenme alışkanlıklarına bakılamamış olması ile açıklanabilir.

Maternal yaş arttıkça GDM sıklığının arttığı bilinmektedir. Literatürdeki çoğu çalışmada 25 yaş sınır olarak alınmıştır. 25 yaşından küçük olanlarda GDM insidansı \%0.4-0.8 iken, yaşı 25 'ten büyük olanlarda \% 4.3-5.5 arasında bulunmuştur $(11,13,14)$. Biz çalışmamızda hastaları 25 yaş altı ve üstü olarak ayırmadık ancak her iki grubun yaş ortalamalarını istatiksel olarak karşılaştırdığımızda grup 1 'in yaş ortalaması 27,6 olarak saptanırken, grup 2 de 32 olarak bulunmuş ve bu fark istatiksel olarak anlamlıdır.

Fetal makrozomi GDM'nin önemli perinatal komplikasyonlarından birisidir. Birçok çalışma maternal hipergliseminin makrozomik bebek doğurma insidansını artırdığını göstermiştir (15-18). Bizim çalışmamızda da literatürle uyumlu olarak grup 1'deki bebeklerin ortalama kilosu 3300 gr, grup 2' deki bebeklerin ise $3457 \mathrm{gr}$ olarak saptanmış ve bu fark istatiksel olarak anlamlı bulunmuştur. Ayrıca makrozomi sınır değerini 4000 gr olarak alırsak, her ne kadar makrozomi endikasyonuyla sezeryana alınanlar grup 1 de fazla da olsa, doğum kilosu $4000 \mathrm{gr}$ ve üzerinde olan bebekler grup $1^{\prime}$ in \%10 unu oluştururken, grup 2'nin \%13 ünü oluşturmaktadır.

Makrozomi ve diyabetik anne bebeklerinde görülen trunkal asimetri enstrümentalvajinal doğum, sezaryenle doğum, omuz distosisi, brakiyal pleksus paralizisi ve klavikula kırığı riskini artırmaktadır (19-24). Bizim GDM saptanan 46 hastanın hiçbirinde enstrümental vajinal doğum veya neonatal olumsuz sonuçlar görülmemiştir. Ancak 46 hastanın sadece 12 $(\% 26,1)$ tanesi vajinal doğumla doğurtulurken $34(\% 73,9)$ hasta sezaryenle doğurtulmuştur. Grup 1'de ise sezaryenle doğum oranı \%44,6 dır. Omuz distosini önlemek için elektif sezaryen yapılması halen tartışılan bir konudur (25). Rouse DJ ve arkadaşlarının yaptığı çalışmada tahmini fetal ağırlığı 4500 gr üzerinde olan diyabetik anne bebeklerindeki bir tane kalıcı brakiyal pleksus paralizisini önlemek için 443 sezaryen yapmak gerektiği bulunmuştur (26). ACOG diyabetik anne bebeklerinde tahmini fetal ağırlık $4500 \mathrm{gr}$ ve üzerinde ise elektif sezaryen yapılmasını önermektedir (9). Bizim hastalarımızda diyabetli gruptaki sezaryen oranlarının yüksek olduğunu düşünmekteyiz. Bu hastaların önemli bir kısmını daha önce geçirilmiş sezaryeni olanlar oluştursa da primer sezaryen oranları grup 2 de daha yüksektir. Bunların içinde diğer endikasyonlar \%29 luk grubu oluşturmaktadır. Bu gruptaki olguları hasta isteği ve anksiyetesi nedeniyle sezaryen yapılanlar ve medikolegal sorunlar nedeniyle kadın doğum hekiminin obstetrik komplikasyonlarla karşılaşmamak için yaptığı sezaryenler oluşturmaktadır. Sezaryen, vajinal doğuma göre yüksek komplikasyon riski olan cerrahi bir operasyondur. Sezaryen oranlarını azaltmak için yapılabilecek en uygun davranış GDM si olan gebelere bu durumun bir sezaryen endikasyonu olmadığı konusunda antenatal eğitim verilmesi ve hekimler üzerindeki medikolegal baskının ortadan kaldırılması olduğunu düşünmekteyiz.

Sonuç olarak biz çalışmamızda hastanemizde takip olan gebelerdeki GDM sıklığını \%8,7 olarak bulduk. GDM hem maternal, hem perinatal komplikasyonları açısından önemli bir medikal durumdur. Anne yaşı önemli bir risk faktörüdür. Günümüzde uygun tarama ve tanı yöntemleri ile tanısı konulup tedavisi yapılırsa perinatal komplikasyonların önlenebileceğini düşünmekteyiz. 


\section{KAYNAKLAR}

1. American Diabetes Association. Clinicalpractice recommendations 2001: gestational diabetes mellitus. Diabetes Care 2001;24(1):77-79.

2. Metzger BE, Coustan DR. Summary and recommendations of the Fourth International Workshop-Conference on Gestational Diabetes Mellitus. Diabetes Care 1998;21(2):161-167.

3. World Health Organization. Definition, diagnosis and classification of diabetes mellitus and its complications. Part 1: Diagnosis and classification of diabetes mellitus. Geneva:WHO 1999(WHO/NCD/NCS/99,2).

4. Nedim Çiçek M, Akyurek C, Çelik C, Haberal A. Kadın Hastalıkları ve Doğum Bilgisi. Diabetes mellitus ve gebelik 2006:435-450

5. Özçimen EE, Uçkuyu A, Çiftçi $F C$, et al. Diagnosis of gestational diabetes melli $\neg$ tus by use of the homeostasis model assessment-insulin resistance index in the first trimester. Gynecol Endocrinol 2008;24(4):224-229.

6. Ferrara A, Kahn H, Qesenberry $C$, et al. An increase in the incidence of gestational diabetes mellitus: North California. Obstet Gynecol 2004;103(3):526-533.

7. Gilmartin A, Ural S, Repke J. Gestational diabetes mellitus. Rev Obstet Gynecol 2008;1(3):129-134.

8. Vambergue A, Dognin C, Boulogne A, et al. Increasing incidence of abnormal glucose tolerance in women with prior abnormal glucose tolerance during pregnancy: DIAGEST 2 study. Diabet Med 2008;25(1):58-64.

9. American College of Obstetricians and Gynecologists. Practice bulletin no. 137: Gestational diabetes mellitus. Obstet Gynecol 2013;122(2):406-416.

10. Couston D. Maternal age and screening for gestational diabetes: a population based study. Obstet Gynecol 1989;73(4):557-561.

11. O'Sullivan JB, Mahan CM, Charles D, et al. Screening criteria for high-risk gestational diabetic patients. Am J Obstet Gynecol 1973;116(7):895-900.

12. Siribaddana SH, Deshabandu R, Rajapakse $D$, et al. The prevalence of gestational diabetes in a Sri Lankan antenatal clinic. Ceylon Med J 1998;43(2):88-91.

13. Marquette GP, Klein VR, Niebyl JR. Efficacy of screening for gestational diabetes. Am J Perinatol 1985;2(1):7-9.

14. Marquette GP, Klein VR, Repke JT, et al. Costeffective criteria for glucose screening. Obstet Gynecol 1985;66(2):181-184.

15. HAPO Study Cooperative Research Group, Metzger $B E$, Lowe $L P$, et al. Hyperglycemia and adverse pregnancy outcomes. N Engl J Med 2008;358(19):1991-2002.
16. Crowther CA, Hiller JE, Moss JR, et al. Effect of treatment of gestational diabetes mellitus on pregnancy outcomes. N Engl J Med 2005;352(24):2477-2486.

17. Kwik M, Seeho SK, Smith C, et al. Outcomes of pregnancies affected by impaired glucose tolerance. Diabetes Res Clin Pract 2007;77(2):263-268.

18. Garner $P$, Okun N, Keely $E$, et al. A randomized controlled trial of strict glycemic control and tertiary level obstetric care versus routine obstetric care in the management of gestational diabetes: a pilot study. Am J Obstet Gynecol 1997;177(1):190-195.

19. Metzger BE, Gabbe SG, Persson B, Buchanan TA, Catalano PA, Damm P, Dyer AR, Leiva A, Hod M, Kitzmiler JL,Lowe LP, McIntyre HD, Oats JJ, Omori Y, Schmidt MI. International Association of Diabetes and Pregnancy Study Groups recommendations on the diagnosis and classification of hyperglycemia in pregnancy. Diabetes Care 2010;33(3):676- 682

20. Landon MB, Spong CY, Thom E, Carpenter MW, Ramin SM, Casey B, Wapner RJ, Varner MW, Rouse DJ, Thorp JM, Jr., Sciscione A, Catalano P, Harper M, Saade G, Lain KY, Sorokin Y, Peaceman AM, Tolosa JE, Anderson GB. A multicenter, randomized trial of treatment for mild gestational diabetes. N Engl J Med 2009;361(14):13391348

21. Lazer $S$, Biale $Y$, Mazor $M$, et al. Complications associated with the macrosomic fetus. J Reprod Med 1986;31(6):501-505.

22. Rouse DJ, Owen J. Prophylactic cesarean delivery for fetal macrosomia diagnosed by means of ultrasonography. A Faustian bargain? Am J Obstet Gynecol 1999;181(2):332-338.

23. Bérard J, Dufour $P$, Vinatier $D$, et al. Fetal macrosomia: risk factors and outcome. A study of the outcome concerning 100 cases $>4500$ g. Eur J Obstet Gynecol Reprod Biol 1998; 77(1):51-59.

24. Stotland NE, Caughey AB, Breed EM, et al. Risk factors and obstetric complications associated with macrosomia. Int J Gynaecol Obstet 2004;87(3):220-226.

25. Culligan PJ, Myers JA, Goldberg RP, Blackwell L, Gohmann SF, Abell TD. Elective cesarean section to prevent anal incontinence and brachial plexus injuries associated withmacrosomia-a decisionanalysis. Int Urogynecol J 2005; 16(1):19-28.

26. Rouse DJ, Owen J, Goldenberg RL, et al. The effectiveness and costs of elective cesarean delivery for fetal macrosomia diagnosed by ultrasound. JAMA 1996;276(18):1480-1486. 